\title{
Computerized occlusal analysis in Dentofacial orthopedics: indications and clinical use the

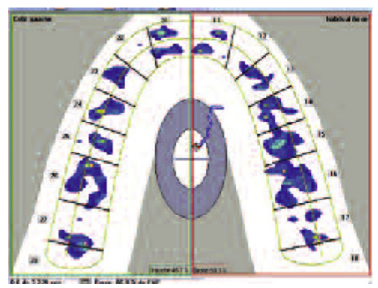 T-scan III system
}

Julia COHEN-LÉVY, Nicolas COHEN

\section{ABSTRACT}

By definition, orthodontists take special care in achieving a high quality occlusion when finishing cases, believing good contacts are essential to maintain dental health, function, and insure stable long-term of results. The T-scan III system provides a real-time digitized analysis of occlusion, in both static and dynamic modes, and records the distribution of occlusal forces within the dental arches in different clinical situations. While the first T-Scan generations versions showed weaknesses, recent technical improvements have made T-scan a reliable and reproducible tool, whose findings are independent of the operator. It is now possible to calibrate the sensitivity of the sensor for individual patients, and to evaluate the quality of records so that comparisons can be made between various stages of a patient's treatment, as well as between patients. In addition to the accuracy of occlusal diagnosis, that often exceed clinical requirements, the T-scan III also can help understanding better each patient's functional pattern. This article describes the T-scan III occlusal analysis system, reviews current literature that evaluated its clinical use, and outlines its principal indications in dentofacial orthopedics. Four clinical cases treated with full bonded lingual appliance will illustrate how the Tscan III influences orthodontic case finishing: one case of "occlusal discomfort" after completion of surgical and orthodontic treatments, a case of cervical abfraction lesions, a case of anterior deep bite restored with an implant-supported prosthesis, and a case of severe facial hemiatrophy treated with a complex protocol.

\section{KEY WORDS}

Occlusion

Lingual orthodontics

Diagnosis

Dental implant 


\section{1 - INTRODUCTION}

Asymmetry

Dental occlusion develops progressively, under the guidance of functional and genetic influences throughout dental arch morphogenesis and subsequently through a variety of adaptations, notably postural and articular. Dealing with complex malocclusions with fixed appliances, orthodontists modify dental contacts to achieve a new position of occlusal equilibrium. Fully aware of the responsibility that this implies, orthodontists devote a special attention to the quality of the final occlusion of their treated cases, irrespective of the therapeutic philosophy to which they adhere (Planas, Ricketts, Roth, Tweed-Merrifield...). Common to all orthodontic philosophies is the demand for esthetics and the restoration of good masticatory and postural function. Many practitioners consider good occlusion to be a bulwark of stable results.

Orthodontists have traditionally evaluated the quality of dental contacts by direct visual inspection supplemented by articulating paper marks. Most do not now routinely employ the time-consuming techni- que of mounting models on articulators, except for some complex cases or for the construction of customized positioner-type retainers.

However, by using new digitized tools like the T-scan III system, orthodontists can now evaluate and register occlusal forces throughout the arches in real time, dynamically, in differing clinical situations.

In this article we describe this analysis system, review the literature detailing studies that have used it, compare its efficacy with articulating paper records, and present an outline of its fundamental principles and applications in dentofacial orthopedics. We illustrate our account with four clinical cases, each treated with a customized bonded lingual appliance: one case of "occlusal discomfort" after combined orthodontic and surgical treatment; a case of cervical abfraction lesions; a case of treatment of anterior deep-bite with an implanted-supported prosthesis; and a case of severe facial hemiatrophy treated with a complex protocol.

\section{2 - THE T-SCAN III SYSTEM}

\section{2-1 - Presenting the T-scan III system}

In 1984, Tekscan Inc ${ }^{29}$ introduced the Windows-compatible, digitized occlusal analysis T-scan system as a method for registering inter-arch oc- clusal contacts dynamically during various mandibular movements, and for representing these in a graphic form in real time, giving information about their duration and their relative force. The system was designed to facilitate diagnosis of occlusal dys- 

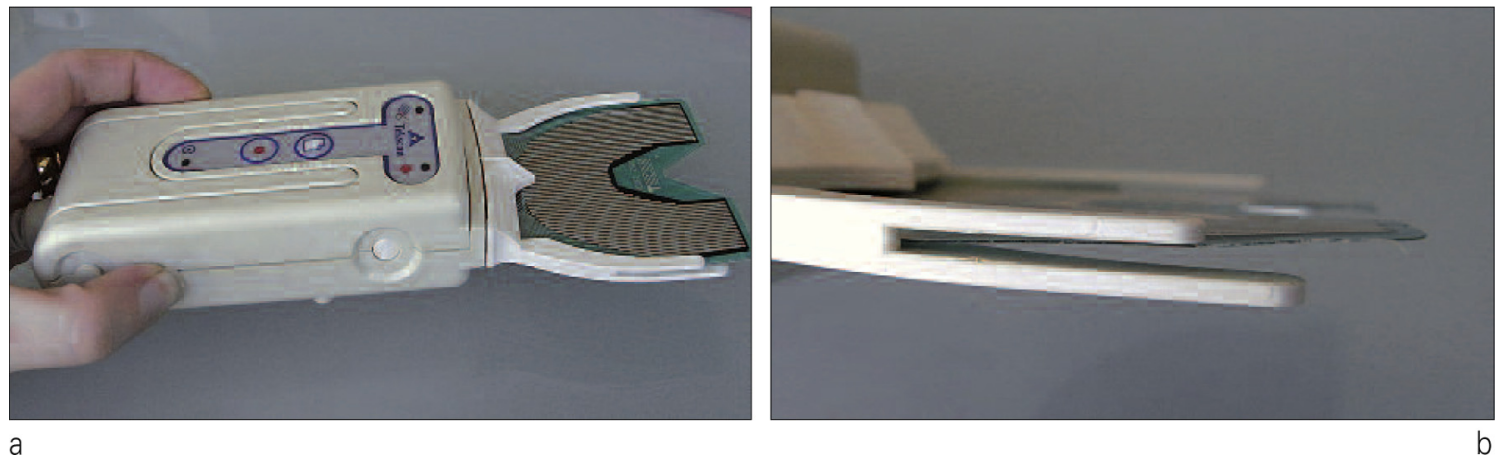

Figures $1 a$ and $1 b$

The T-scan III system.

a: The T scan III system consists of a disposable sensor, an autoclavable occlusal adaptor, connected to an electronic sleeve to the USB port of a laptop computer.

$b$ : the sensor is $85 \mu \mathrm{m}$ thick and flexible.

function and to guide practitioners in delivering occlusal equilibration of natural and prosthetic teeth and, especially, of implant-supported prostheses 23,29 .

The T-scan system consists of a thin flexible sensor inserted into an autoclavable sensor handle that is plugged into the USB port of a personal computer (Fig. 1a).

The slim horseshoe-shaped sensors, which can be used repeatedly for a single patient, are made up of 1370 active pressure sensing locations (1122 pressure sensing locations for small sensors). Eighty-five microns thick (Fig. 1b), it encloses a double layer of Mylar, a special ink. A force applied to each of these cells modifies the electric conductivity of the Mylar. The program records and analyzes the differentials of applied voltage, and gives relative values of the force and duration of occlusal contacts, with a time precision of $10 \mathrm{~ms}$.

The results are delivered in the form of graphs describing force variation with time; force histograms are projected on an individualized dental arch (that can be modified according mesio-distal tooth dimensions or missing teeth) allowing the practionner to picture the location and duration of inter-arch contacts over time.

Before bite registration, one must calibrate the sensitivity of the T-scan to accommodate the patient's muscular force such that the system can detect very light contacts without becoming saturated by heavier contacts.

In the first example, we present the case of a patient who was experiencing "occlusal discomfort" after the removal of orthodontic appliances. We had treated her with a combined surgical and orthodontic non-extraction approach for a Class II division 2 malocclusion (Figs. 2a-3c and 3a-3c. Dr. O. Esnault, Paris, was the maxillofacial surgeon). The patient was included in a clinical study $^{7}$. We made various T-scan registrations for this patient, first on the day on which the lingual attachments were removed, and then at 3 and 6 months into the retention period (Fig. 4a-4c). 


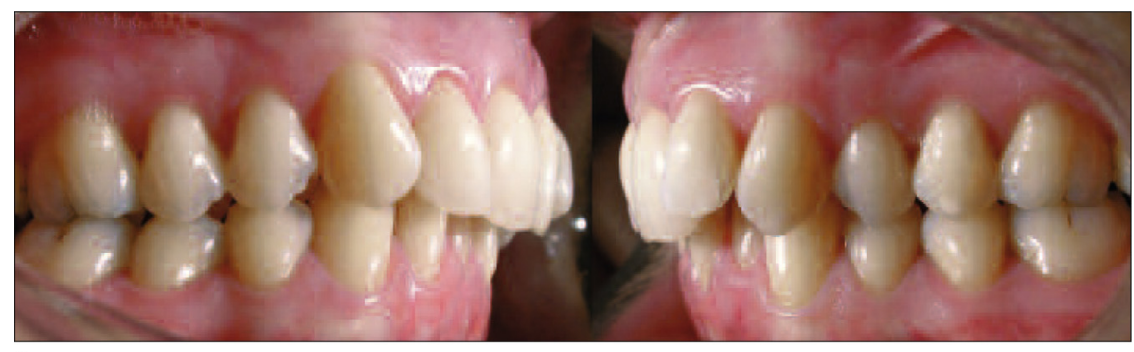

a

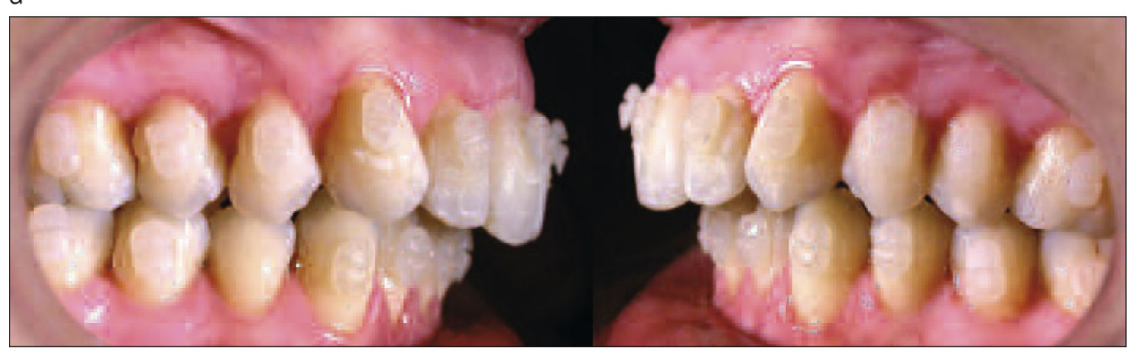

$\mathrm{b}$

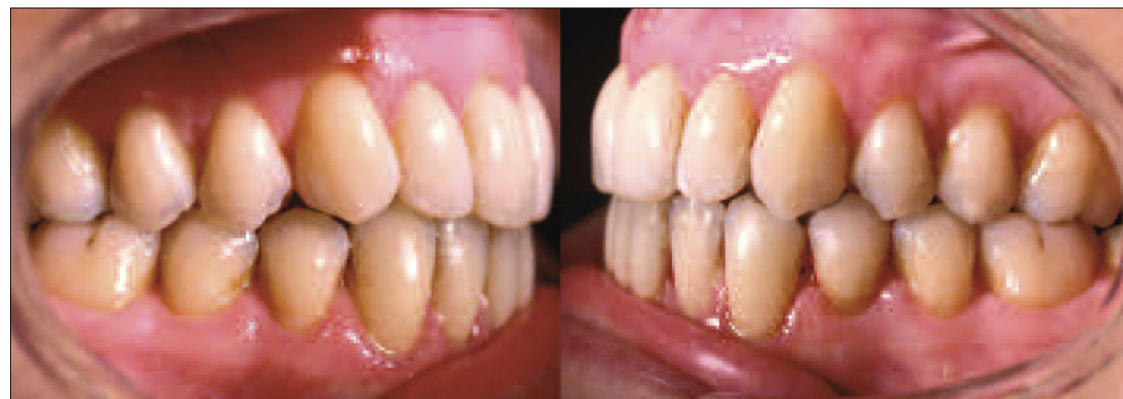

C

Figures $2 a$ to $2 c$

Clinical case 1: Intraoral views of a Class II division 2 malocclusion treated by a combined surgical-orthodontic protocol with a customized lingual appliance technique.

a: Before treatment. The extruded position of the mandibular anterior teeth seems to be the principle component of the anterior overbite.

b: Pre-surgical situation showing clear bonded buttons in place on both arches.

c: Post-treatment. Note the slight canines's infra-occlusion.

Immediately after appliance removal, we bonded an anterior lingual retention wire and proceeded to the first registration; there were no contacts in the anterior region of the arch, so that occlusal forces were exerted primarily on the molar teeth, weakly on the bicuspids, and most forcibly on the right side. The upper and lower right second molars sup- ported $41 \%$ of the total force discerned by the sensor. This initial distribution signified a slight anterior open bite that we interpret as resultant from the differential in thickness between the upper lingual attachments and that of the bonded retention wire that replaced them. Accordingly, the marks made by ar- 

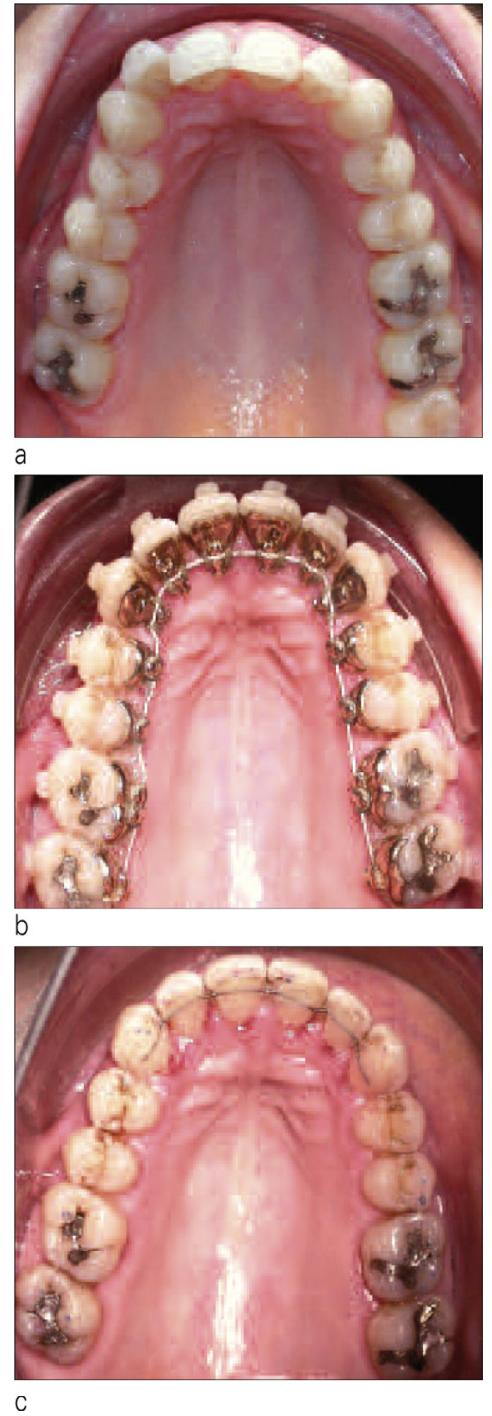

Figures 3a to $3 c$

Clinical case 1: Occlusal views of the maxillary arch. a: Before treatment.

$b$ : Pre-surgical. Note the bite planes incorporated in the canine lingual attachments to help leveling of the mandibular arch.

c: Appearance on the day of appliance removal, with a lingual retention arch wire bonded between the maxillary canine, and the occlusal marks made by Bausch two-sided articulating paper. Note the clear marks on the molars and the weaker marks on the left second bicuspid and the right cuspid. The incisal marks appear to be false positives caused by folding over of the articulating paper. ticulating paper on the canines were false positives.

At the 3-month check-up visit, the patient described a feeling of uneven contact between the upper and lower molar teeth on the right and left sides that was not apparent from articulating paper markings (as shown in the intraoral view of the maxillary arch in Figure 3c). Even though postorthodontic physiological eruption ("settling") brought the upper and lower anterior teeth into contact, the force of their occlusion remained weak, and the right side occlusion took $66 \%$ of the total contact forces, demonstrating its dominance. The center of force, depicted by a diamond, has clearly shifted to the right.

At 6 months (Fig. 4c), we relieved high spots on the amalgam filling in the upper right second molar to reduce the force sustained by this single tooth and to encourage a better distribution of occlusal forces. We had noted how the histogram tracings of forces exactly followed the shape of the occlusal portion of the amalgam restoration. However, the asymmetry of inter-arch contacts persisted and their distribution throughout the maxillary arch remained unchanged.

Because of the absence of clinical signs and the eradication of occlusal discomfort, we undertook no further equilibration despite the residual asymmetry in the occlusal forces. We encouraged the patient to continue the physiotherapy exercises prescribed after her maxillofacial surgery, and asked her to balance her mastication between the right and left sides to eliminate functional asymmetry. 

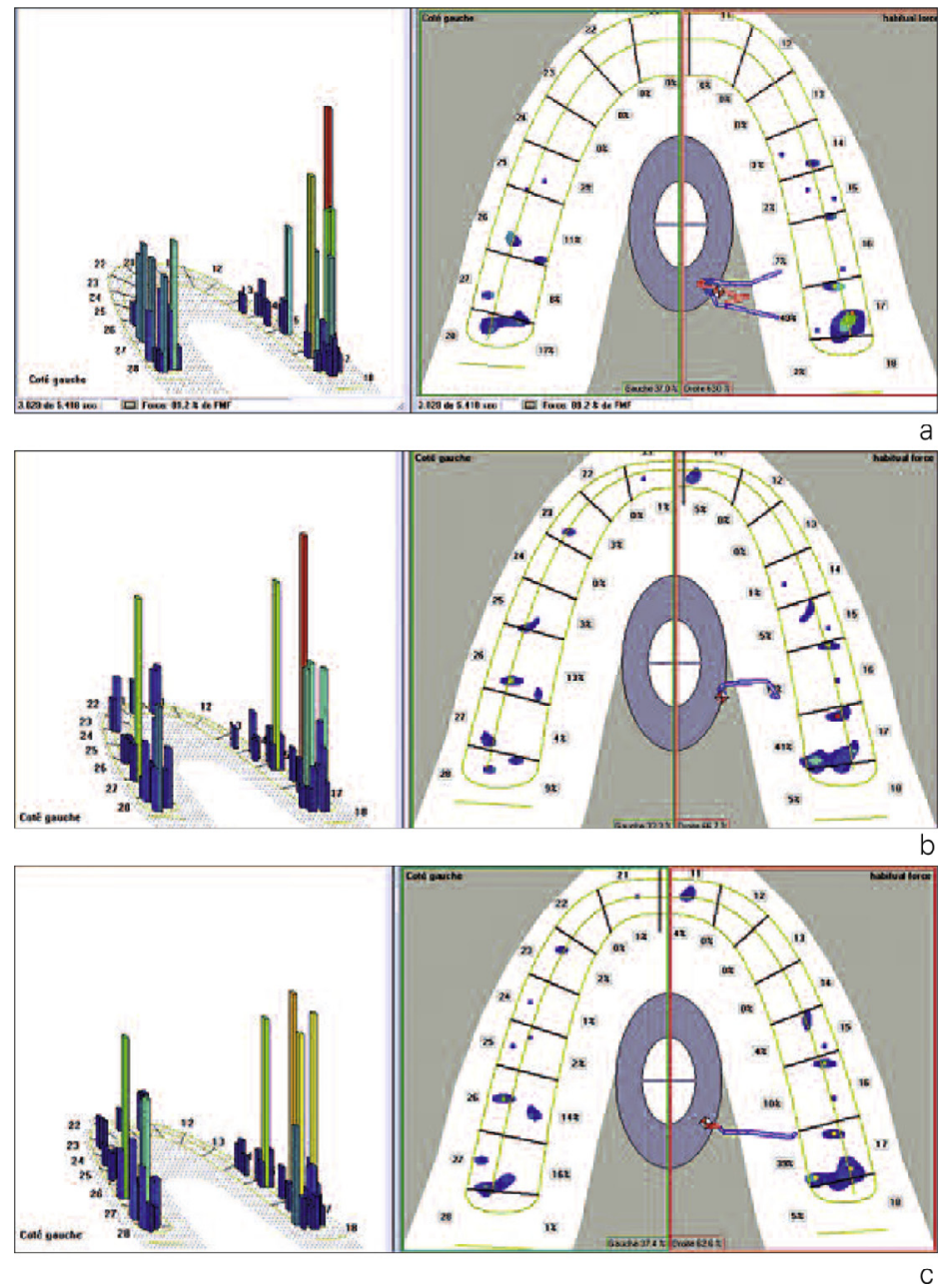

Figures $4 a$ to $4 c$

Clinical case 1: T-scan III registration, occlusal view.

a: On the day of appliance removal only posterior teeth, primarily the molars, are in contact with their antagonists. Contact between upper and lower bicuspids is weaker. The red diamond shows clearly that the center of force has drifted to the right, and shows oscillations.

b: Three-month recall visit. Note that the upper and lower anterior teeth have begun to come into contact because of physiological extrusion. The center of forces is still located on the right but with fewer oscillations. The contact between the upper and lower second molars is still strong.

c: Six-month recall visit. The patient's sense of occlusal discomfort was eradicated by equilibrating the amalgam filling on the occlusal surface of the maxillary right second molar. The occlusal forces are more balanced but still somewhat heavier on the right. The upper right lateral incisor and canine teeth are still out of contact with their lower antagonists. 


\section{2 - 2 - Scientific validation of the T scan system}

The first generation of T-scan sensors had certain weaknesses, principally high variability in their physical properties, with sensitivity not distributed uniformly across the sensor. Consequently, they often disclosed fewer contacts than were revealed by articulating paper. Reliability and sensitivity studies reported disappointing clinical results for early Tscans $^{17,18}$. The next two generations of sensors were thinner and had greatly improved resolution and sensitivity, especially for extreme pressure values ${ }^{22}$. Other studies showed that these much-needed improvements had made the instrument more reproducible and sensitive 22,23 .

A German research team validated the clinical use of the T-scan on 42 adult subjects ${ }^{24}$, estimating its error of measurement as $1 \%$, its precision error as $2 \%$, and its reliability error as $2.8 \%$. They also asserted that changing the sensor or repeating the tests had no effect on the measurements obtained.

\section{2 - 3 - A comparative analysis between digitized occlusal force results and results from traditional methods}

Clinicians have traditionally used articulating paper and patient's feedback to guide occlusal equilibration. Despite widespread use, these meth- ods had limitations, as illustrated in several clinical and research articles.

Articulating paper can pinpoint the location of contacts between antagonistic teeth if the ink transfers correctly from paper to tooth. However, as we have noted, this inevitably produces a number of false positives.

Marks made by articulating paper can vary in size and shape, in deepness of color, or appear as a ring with a clear center like a halo ${ }^{20}$, and can be interpreted in multiple ways. Differences in the intensity of marks may represent differences in force intensity or could simply reflect the specific occlusal morphology or the condition of the occlusal enamel or restoration surface. Variations in articulating paper marking may also arise from differences in paper thickness, the extent to which it is impregnated with saliva, and the force of the patient's bite. Because of these types of variation, many researchers have been able to demonstrate that contact profiles determined using articulating paper are not reproducible, even when made under apparently identical conditions ${ }^{9,20,31,38,39}$. Furthermore, Rozencweig et al. ${ }^{37}$ have shown that the storage conditions of articulating paper in the dental office can contribute to variation in markings. Repeated utilization, probably because of saliva impregnation, can significantly reduce its precision and sensitivity, regardless of the type of support employed ${ }^{39}$. In contrast, Tscan is totally unaffected by moisture $^{39}$. 
Dentists often interpret large marks as an indication of strong forces, which is a false conclusion in most cases. In a pilot experimental study on the subject ${ }^{9}$, researchers mounted models on articulators and subjected them to forces of increasing intensity. They found only a $21 \%$ probability that two similar marks were generated by the same force (between $25 \mathrm{~N}$ and $450 \mathrm{~N}$ ). Another study, conducted in 2008, comparing the effect of articulating paper thickness $(25 \mu \mathrm{m}$ or $60 \mu \mathrm{m})$ on contact marking at pressures ranging from $100 \mathrm{~N}$ to $200 \mathrm{~N}$, found there was no significant increase in the number or size of the marks with increased pressure for either thickness of paper. As expected, the thicker paper created more marks, which were generally of larger size than with thin paper $^{38}$.

In summary, the marks made by occlusal articulating paper are difficult to reproduce and should no longer be considered as accurate reporters of generated occlusal force, their primary purpose now being the qualitative location of contacts or near contacts between opposing teeth.

The possibility of using a digitized analysis such as that offered by the T-scan system is extremely attractive because it eliminates the factor of operator subjectivity. Other computerized methods are also available including the Prescale Occlusal System $^{\text {TM }}$ (Ref. 31). Alternatively, lowviscosity impression materials such as Blu-Mousse ${ }^{\mathrm{TM}}$ can be used, with the need of a scanner and computer.

\section{$2-4$ - Clinical use of the T-scan III system}

\section{- Analysis of contact marks made in intercuspation}

Having chosen and calibrated a sensor for an individual patient, the practitioner begins registration of an occlusal sequence by keeping the sensor in place within the maxillary incisors' embrasures. It is advisable to register a number of consecutive bites on the sensor because many hesitant patients begin by biting very tentatively.

After practitioners complete the registration, they can visualize the digitized results from various perspectives:

- a view of the arch upon which the forces exerted are represented by color histograms (Fig. 4);

- a familiar occlusal view resembling the picture given by articulating paper (Fig. 4) and,

- two graphs that illustrate the development of forces over time, as shown below.

Time is expressed in milliseconds on the abscissa, while the ordinate shows the forces received by the sensor, ranging between 0 and $100 \%$. The gray graph denotes the totality of the forces recorded by the sensor, while the color graphs represent different sub-sectors of the dental arch that can be divided into right (pink) and left (green) or into quadrants. Note that these different graphs show a phase of growing occlusal force upon closure and first contact, a plateau phase of maximal 
intercuspation, and a diminishing phase as the mouth re-opens. In the occlusal view of contacts, the diamond represents the center of force and the adjoining tracing shows its movements during the registration.

The Center of Force (COF) is the center of "gravity" of the pressures recorded by the sensor and not an indicator of mandibular position. The tracing of mandibular movements, or "oscillations", denotes the balance of forces between the first and last contacts. In theory, it should be positioned in the median sagittal axis for registrations of maximal intercuspation and for patients with full dentures.

\section{- Dynamic analysis}

An important and useful feature of the T-scan is its ability to register occlusal contacts during mandibular excursive movements in real time, eliminating any need for mounting models on an articulator (the traditional method for obtaining this information).

A Chinese study ${ }^{40}$, published in August 2011, reported dynamic Tscan analyses of the occlusion of 85 students with Class I occlusions. In the three positions (lateral disclusion, edge to edge canine position, and maximum lateral amplitude), six different occlusal schemes were described, going beyond the notions of canine protection and group function. It may thus be possible to formulate new norms but new clinical applications for these findings have yet to be found.

To illustrate this analysis, we present the case of a patient treated orthodontically for a Class I malocclusion with a Class III tendency, an arch length discrepancy, an anterior cross bite, and abfraction lesions in the posterior area. Because of chipped incisal edges and the small size of the maxillary lateral incisors, bonded veneers for the upper anterior teeth were included as a component of the treatment plan.

Figures $5 a-d$ depicts the initial clinical situation, while Figures 6a-6d show intraoral views of the results of orthodontic treatment. Figures $7 a-7 d$ are maxillary occlusal views at various stages of treatment (before; nearing completion of treatment when the bonded lingual attachments were still in place; after treatment showing articulating paper marks and a bonded cuspid-to-cuspid wire retainer; and the final appearance of the arch after bonding of veneers to the upper lateral incisors). We show an example of right lateral movement as perceived clinically in Figure $8 \mathrm{~d}$ on the working side and in $8 e$ on the non-working side, the photograph illustrating canine protection taking the buccal teeth well out of occlusion, at least in the final phase.

The T-scan registration depicting this right lateral movement is shown in three screen shots, taken at different time frames:

- At the beginning of lateral movement, as the upper and lower cuspids come into contact, there is an excellent balance of occlusal forces, albeit slightly dominated by the left side (Fig. 8a).

- Group function can be noted on the right side, with slight premolar interference on the non-working side at the end point of lateral disclusion. The amplitude and dura- 


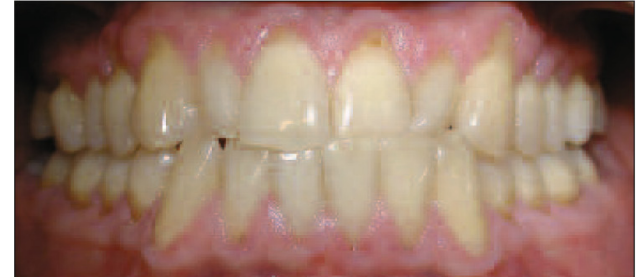

a

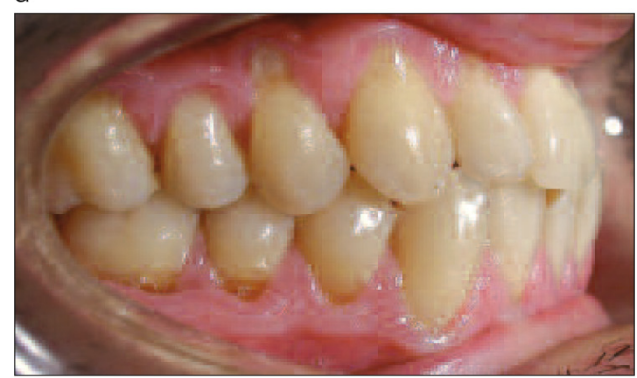

C

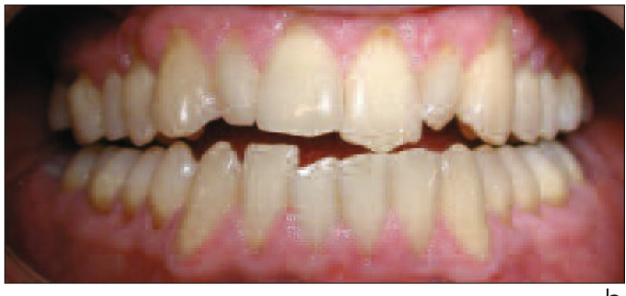

$\mathrm{b}$

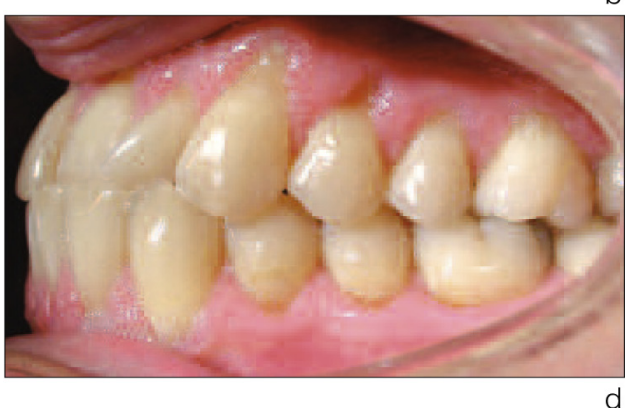

Figures 5 a to $5 d$

Clinical case 2: Intraoral views of a case of Class I malocclusion with anterior cross bite, gingival recession with cervical abfraction lesions (restored on the left side, marked on the right side) and fractures of incisor's incisal edges.

a: Frontal view,

b: jaw slightly open,

c: right view, teeth in occlusion,

d: left view, teeth in occlusion.

tion of these premolar contact interferences are both weak (Fig. 8b).

- Only the right cuspids are in contact, which is of moderate intensity, at the end point of lateral movement (Fig. 8c).

The trajectory of the center of force is, not surprisingly, located on the right side, between the canine and the first bicuspid, but is not frankly oblique. The curves describing sensor loading on the right side (red) and left side (green) cross over, illustrating the dis-occlusion of the left cuspid sectors, and the sensor loading on the right side. With T-scan III registrations, it is possible to follow the distribution of contacts at $10 \mathrm{~ms}$ intervals.

\section{- Searching for interferences in centric relation}

In the preceding registrations, which were made with no manipulation by the practitioner, our objective was to find a free expression of occlusal forces by eliminating, as much as possible, any interference with natural mandibular movement. The search for interferences in the mandibular closing pathway between terminal axial position and a convenience bite requires, however, that practitioners exert a gentle manipulat- 

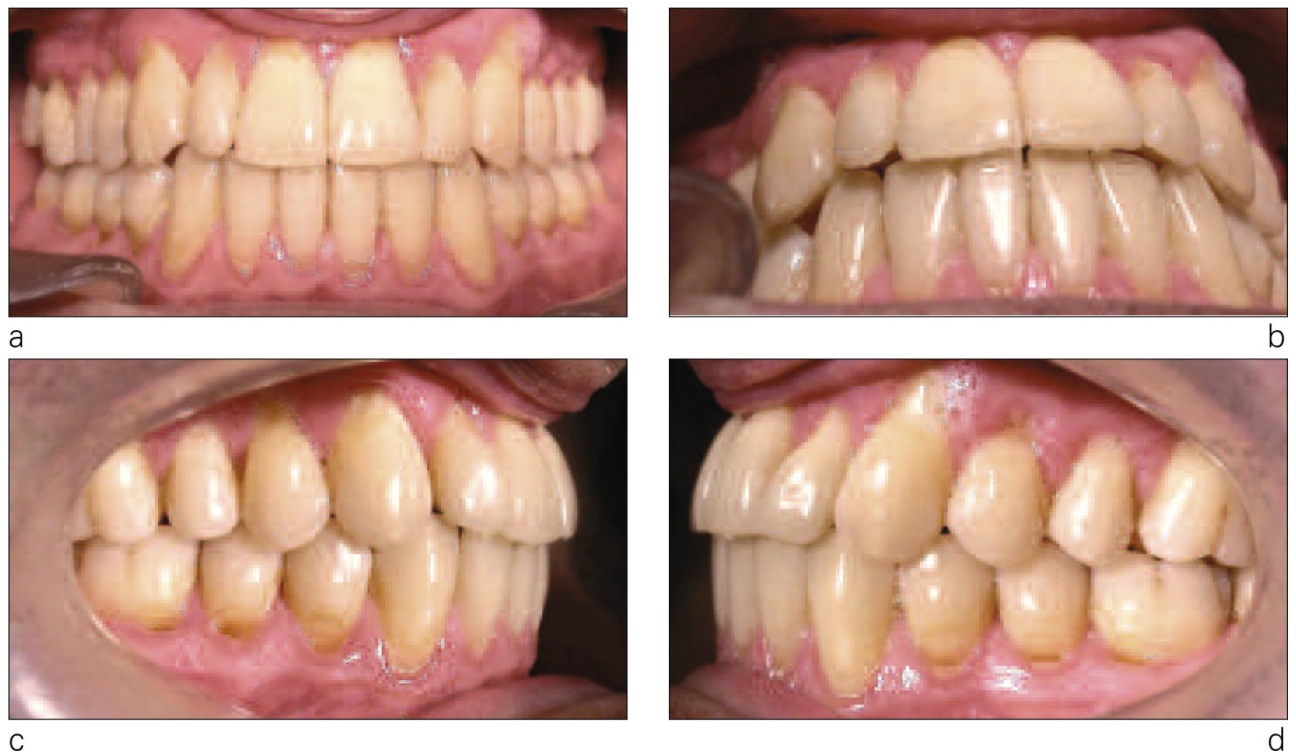

Figures 6 a to $6 d$

Clinical case 2: Occlusion at the end of treatment.

ing pressure of weak amplitude on the mandible, through which they "feel" the first contact. However, T-scan III has a special application, more sensitive, designed for this type of registration and that can record the weakest pressure values.

This analysis system is easy to use in the sense that a dozen consecutive movements can be made, con- centrating on tactile sensations, with no insertion and removal of paper, only later controlling the repetitive character of the results. However, the need to use articulating paper is not completely eradicated; it must still be used to visualize effectively the desired contact once it has been located and clearly quantified.

\section{3 - INDICATIONS FOR DIGITIZED OCCLUSAL ANALYSIS IN DENTOFACIAL ORTHOPEDICS}

\section{3 - 1 - Temporomandibular disorders (TMD) and T-scan III}

\section{- Diagnosis}

Temporomandibular disorders are multifactorial in origin and are now thought to resemble chronic musculoskeletal pain disorders in other parts of the body, such as the lower back, whose etiology has a large psychological component ${ }^{1}$. Suppliers and manufacturers have proposed different methods for diagnosing TMD, 


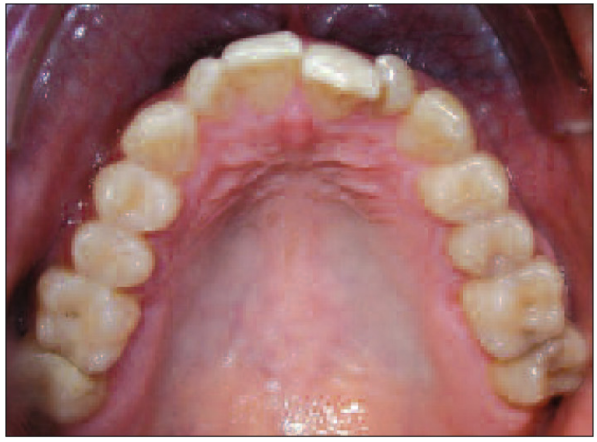

a

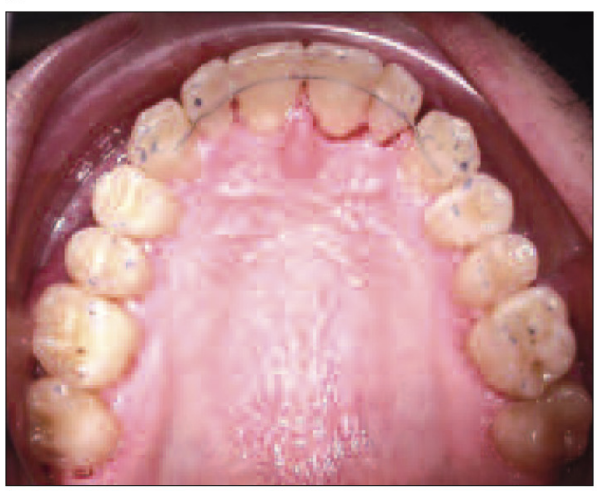

C
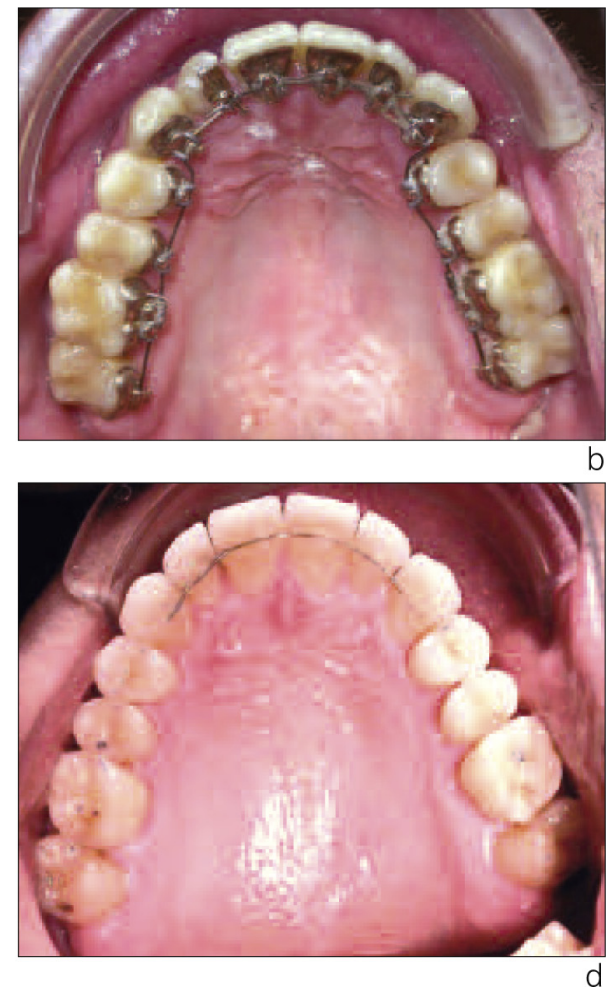

Figures $7 a$ to $7 d$

Clinical case 2: Views of the maxilla.

a: At the beginning of treatment,

b: near the end of treatment, showing lingual bonded attachments,

$c$ : at the end of treatment with articulating paper markings, 3-to-3 bonded retention wire,

$d$ : after placement of anterior veneers.

suggesting registrations of muscular activity $^{21}$, the rest position of the mandible ${ }^{11}$ or the recording of occlusal interferences, an area in which Tscan III could be useful.

Analysis of the validity, reliability, and utility of these techniques ${ }^{4}$ is currently a controversial subject, partly because clear cost-benefit demonstrations have yet to be made.

The issue of over-diagnosis of TMD or, more gravely, of over-treatment is important because no one has yet accurately described the clinical significance of different TMD anomalies. The American Association for Dental Research ${ }^{1}$ recommends that practitioners essentially base their diagnoses on the anamnesis and clinical examination, completed if indicated by X-ray films.

One 1994 study, published by a Japanese team ${ }^{32}$, using the T-scan III noted a difference between patients affected by TMD $(n=5)$ and a control group $(n=60)$. In the control group, the duration and distribution of contacts were symmetrical with centers of force clustered around the first molar. In the TMD group, the force and duration of contacts were asymmetrical, with centers of force 


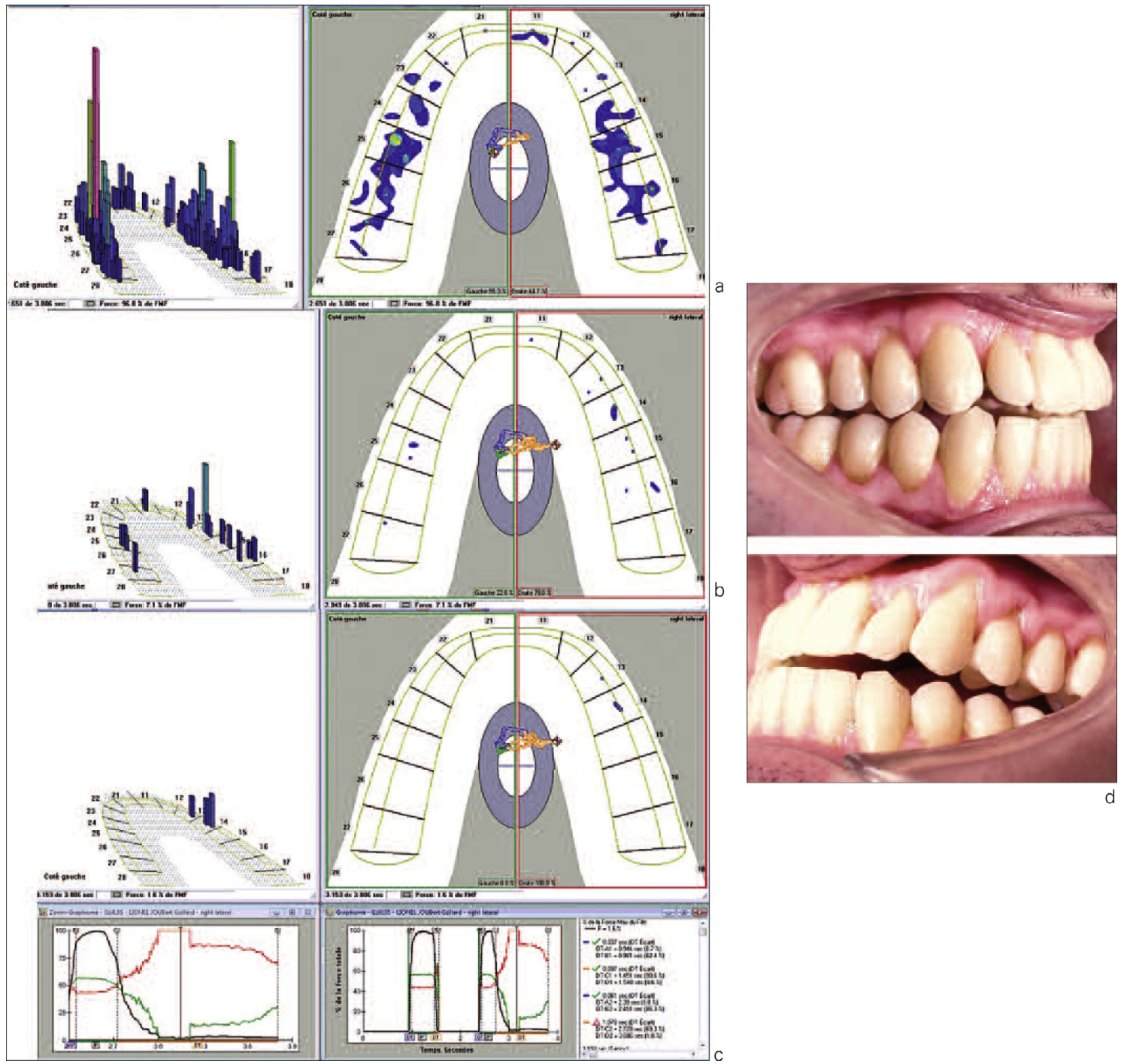

Figures 8 a to $8 d$

Clinical case 2: T-scan III registration.

a: Maximal intercuspation showing the well-balanced distribution of inter-arch contacts, with the center of force on the median line;

b: Beginning of lateral movement, with group protection (canines and premolars contacting on the right side) and interference of the left premolars on the non-working side;

c: Final extension of lateral movement with only canines in contact, and other teeth dis-occluded. The canine guidance facet can be seen;

$d$ : Dis-occlusion on the left side.

in varied locations. This study, however, does not provide us with a reliable assessment of the diagnostic value of T-scan III because of numerous methodological faults (e.g. low subject numbers, failure to randomize 
groups and maintain their anonymity, and inadequacy of the definition of inclusion factors).

In summary, T-scan III provides a means of discerning anomalies in the centering and intensity of occlusal forces that reflect functional asymmetries and muscular spasms. However, it is only to be used to supplement, not substitute for, anamneses, clinical examinations, and radiographic imaging. In addition, because of the visual clarity with which its findings are presented, it constitutes an excellent tool for communicating results and concepts with colleagues and patients.

The vagaries of the center of force and the irregular character of the sensor loading can be reviewed in later appointments after patients have undergone oral health training with physical therapy ${ }^{7}$, to help them resolving their TMD problems through their own efforts.

\section{- Treatment}

Mechanistic thinking has for years persuaded many dentists that the etiology of TMD is structural, and was caused exclusively by occlusal discrepancies and poor condylar positioning associated with disturbances of neuromuscular or postural balance. This mindset led them to attempt to treat TMD with orthodontic, surgical, and prosthetic therapy, the sole goal of which was to correct temporomandibular symptoms.

Nowadays, most practitioners realize that TMD develops according to a normal cycle with active phases, when pain and discomfort can have a significant effect on patient's life quality, and improvement phases, with spontaneous remission even in the absence of treatment.

Controlled studies, in the "evidence-based" concept, have not drawn the conclusion that patients need a permanent "correction" of their occlusion or the relations of their condyles to be cured of $\mathrm{TMD}^{14}$. Despite their symptoms, patients with internal defects of the TMJ do not ordinarily require treatment because most respond well to physical therapy' ${ }^{2,14}$ and pain management.

Published papers analyzing the quality of clinical studies, notably the Cochrane Reviews, emphasize the lack of statistical power and the methodological flaws in TMD studies so far available $1,26,27$. These critics explain that it is not yet possible to make recommendations for clinical practice in this domain, and accordingly, in the current state of knowledge, they cannot approve orthodontic or surgical treatment whose sole goal is to ameliorate symptoms associated with the TMJ. They admit that this stance may change should new research provide evidence of the efficacy of such therapy.

In parallel, however, is a broad agreement that therapy, be it orthodontic, restorative, or prosthetic, should favor proper intercuspation, encourage free movement of the mandible, and avoid placing the mandible in a distal position that can cause articular constraints ${ }^{35}$. Practitioners should search in their examinations for oral habits or behavior like bruxism that impose an unhealthy overload on the masticatory system. 


\section{3 - 2 - Follow-up of post- orthodontic occlusal changes}

Several studies have been devoted to the quality of static and dynamic occlusion after orthodontic treatment and to the influence of various types of retainers ${ }^{7}$. After removing appliances it is tempting for orthodontists to leave teeth unretained because that will allow for spontaneous improvement of certain parameters like the attainment of more contact points and the leveling of marginal ridges. However, without the placement of fixed or removable retainers, the risk that rotations or overbites could relapse and require retreatment is too great to be acceptable ${ }^{28}$.

By using tooth positioners made from a perfected set-up mounted on articulators, orthodontists can improve the equilibration and intercuspation of cases treated with asymmetric or atypical extractions because of arch length discrepancies $^{13}$.

Weak anterior inter-arch contacts usually represent something other than poor finishing of an orthodontic case (as was true in our first case, Figs. 2-4). They resemble the usual T-scan findings of individuals who had no orthodontic treatment, where markings of lateral incisors are difficult to find in maximum intercuspation. In a mutually protected occlusion, it is normal to obtain weak anterior markings and much stronger posterior ones in intercuspation because molars, with their broad-based root surfaces, are designed to accept a large proportion of the total occlusal load. It is only during the course of anterior and lateral excursive movements that incisors and canines support occlusal forces as molars are taken out of occlusion.

A Chinese team ${ }^{3}$ studied inter-arch contacts at different force levels for two groups of subjects with normal occlusion: a group of patients who had been treated with pre-adjusted brackets (edgewise technique) and arch wires, and another with subjects who had never had orthodontic treatment. They found that anterior force levels were significantly higher in the treated subjects than in the control group, although this had no clinical significance.

Another (longitudinal) study, performed in adults who had been treated with an individualized lingual appliance ${ }^{7}$, demonstrated that the occlusal forces of a great majority of these patients tended to become symmetrical over time. However, in some patients a marked asymmetry in the force of contacts on the right and left sides persisted to an astonishing extent. Marks left by articulating paper could not have discerned these subtle distinctions, which can only be revealed through the reliably reproducible results from a digitized sensor.

The clinical significance of these observations is obscure because no one has yet been able to associate them with any oral disorders. However, it is unequivocal that these results project a surprising, different view of functional occlusion. For example, sensors can specifically search out the location of the center of force and the balance of contacts, as the following case study indicates. 
This patient was afflicted with Parry-Romberg hemifacial hypotrophy syndrome, a strong disfiguring facial asymmetry involving skeletal structures, muscles, and the dental arches $^{8}$ (Fig. 9). Her complex combined surgical and orthodontic bimaxillary treatment was supplemented by lipo-filling injections given by Dr. D. Defrennes, of Paris, to restore balance to her distorted facial features. We employed a mixed fixed orthodontic technique that used individualized lingual bonded attachments on the upper arch and buccal bonded ceramics on the lower jaw, adapting our treatment to accommodate the possible loss of some anterior teeth that, at the start of therapy, had practically no roots (Figs. 10 and 11).

Figure 12 depicts the surgical arch wire, while the clinical change after the removal of appliances and at the end of the retention period (2 years post-operative) is shown in Figures 13 and 14, respectively. Figure 15 portrays the distribution of inter-arch contact points at the time of appliance removal and 2 years later. The occlusal forces were highly lopsided on the day of debonding, with $80 \%$ being concentrated on the right side. Adding composites to the hypoplastic bicuspids brought the inter-arch contacts into improved balance.

At the end of the 2-year retention period, the teeth affected with phantom roots were still in place, and exhibited negligible mobility. The patient was advised that these might imminently need to be replaced with implants but are currently maintaining space and preserving alveolar bone. Inter-arch contacts still show right side dominance and their distribution is unchanged. The charging of the sensor is now regular as the forces become uniform throughout the arch as they increase in amplitude. Taking into account the serious effect this syndrome has on the patient's musculature, we felt it was important to ensure that symmetric function was achieved as well as morphological symmetry.

The necessary physiological adjustments of the patient's masticatory system and occlusion may require longer than a year to become firmly established following combined orthodontic and surgical treatment ${ }^{19}$.

\section{3 - 3 -Occlusal trauma as an etiological factor}

It has been suggested that eccentric occlusal forces could be a factor in the etiology of abfraction cervical lesions and that the existence of occlusal micro-trauma could have a deleterious effect on periodontal tissues and osseointegrated implants. To prevent such undesirable outcomes, occlusal equilibration has been suggested as the treatment modality.

\section{- Abfraction lesions}

Abfraction lesion is a type of noncarious cervical lesion that causes a loss of hard dental tissues that sometimes require restoration of surrounding crown and root areas. They differ from other cervical lesions caused by abrasion or erosion and develop in response to flexion, which is an excessive, cyclic loading perpendicular to the long axis of teeth. Constraints concentrate in the cervical region of the tooth where 

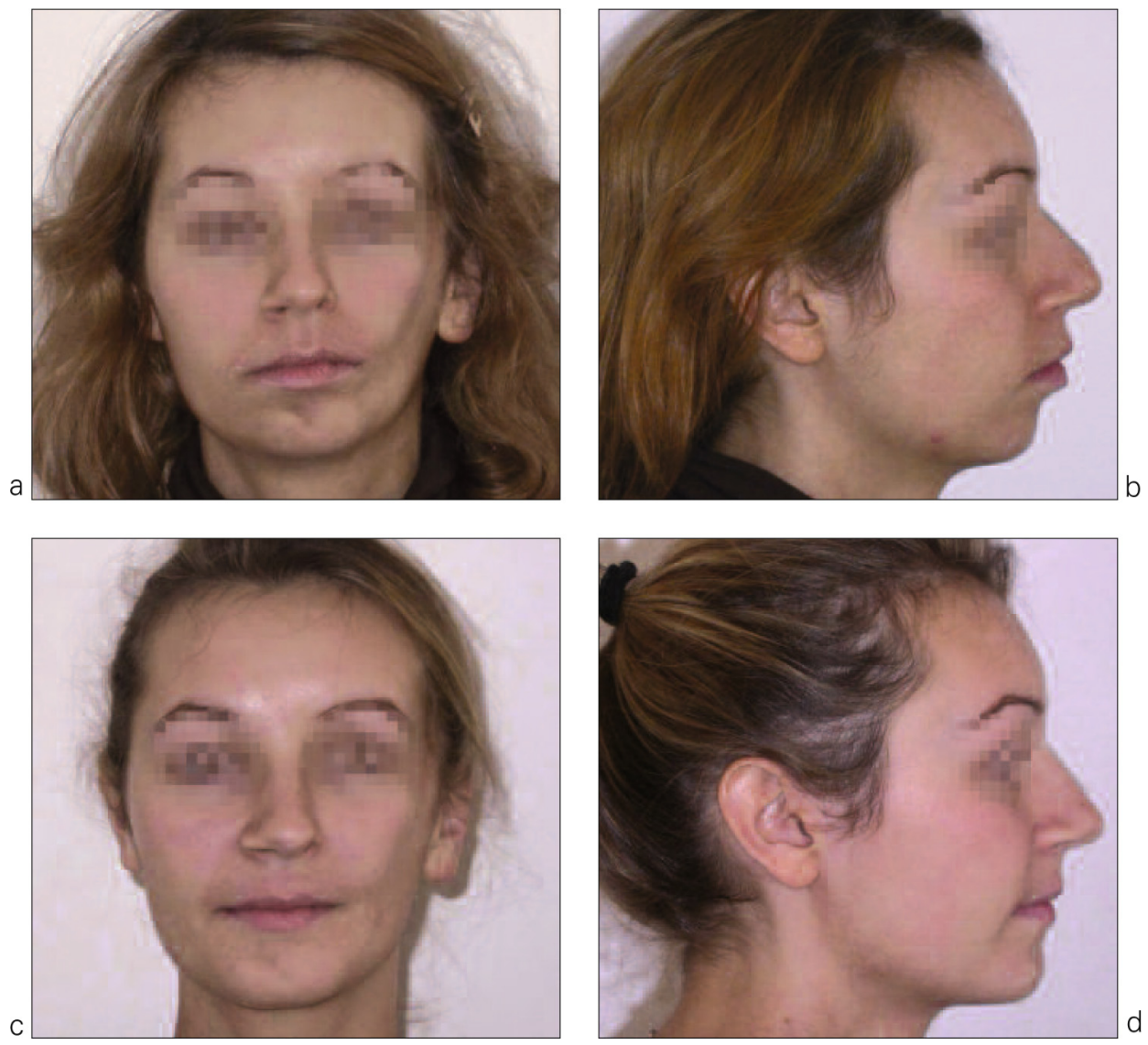

Figures 9a to $9 d$

Clinical case 3: Facial views of a patient with Parry-Romberg syndrome before (a and b) and after (c and d) combined surgical-orthodontic treatment and lipo-filling lautogenic fat graft) on the hypoplastic side.

the enamel layer is thin and readily fractured.

Most theories explaining abfraction lesions are derived from finite element models but there is virtually no experimental proof to substantiate them. Clinical studies have shown that they are associated with bruxism, wear facets, and premature contacts but no investigations have been able to confirm any causal relation$\operatorname{ship}^{15,30}$.

In an investigation of 46 subjects $^{5}$, one research group evaluated the relationship between premature contacts in centric relation and the development of abfraction lesions. The majority of both abfraction lesions and high spots were located in the premolar area. The teeth affected by abfraction lesions had significantly 


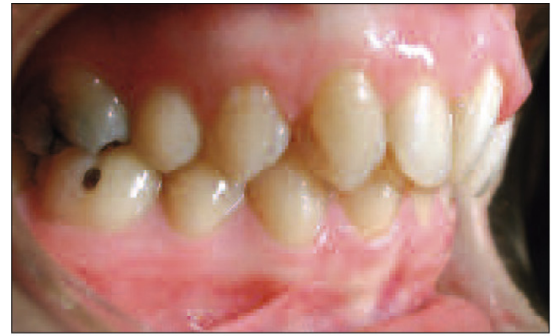

a

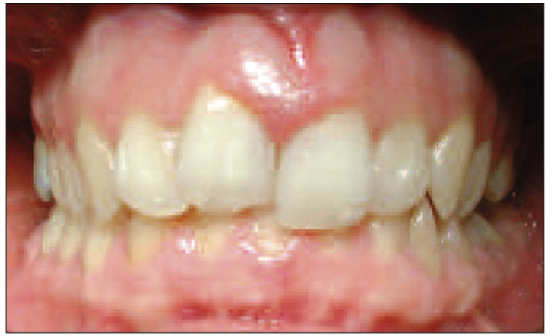

b

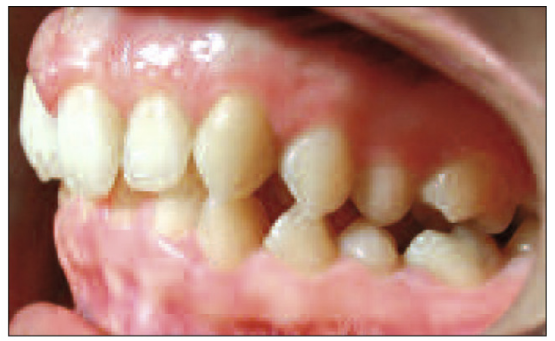

C

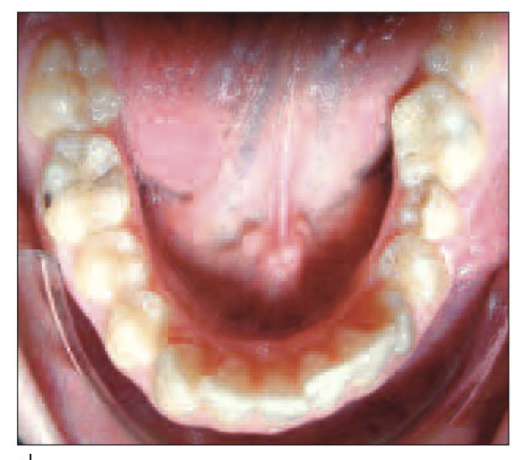

d

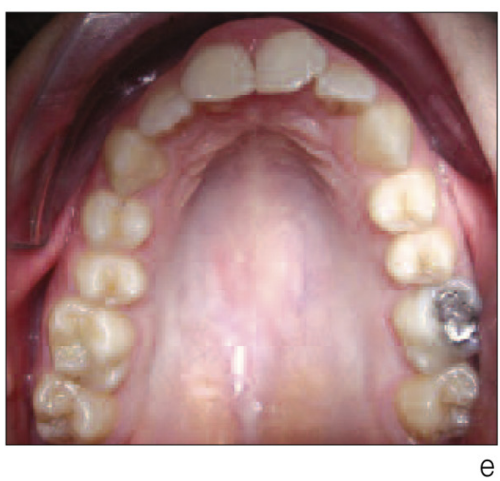

Figures 10a to $10 e$

Clinical case 3: Intraoral views at the beginning of treatment showing the asymmetric sagittal relationships and the hypoplasia of the lower left cuspid and bicuspid teeth.
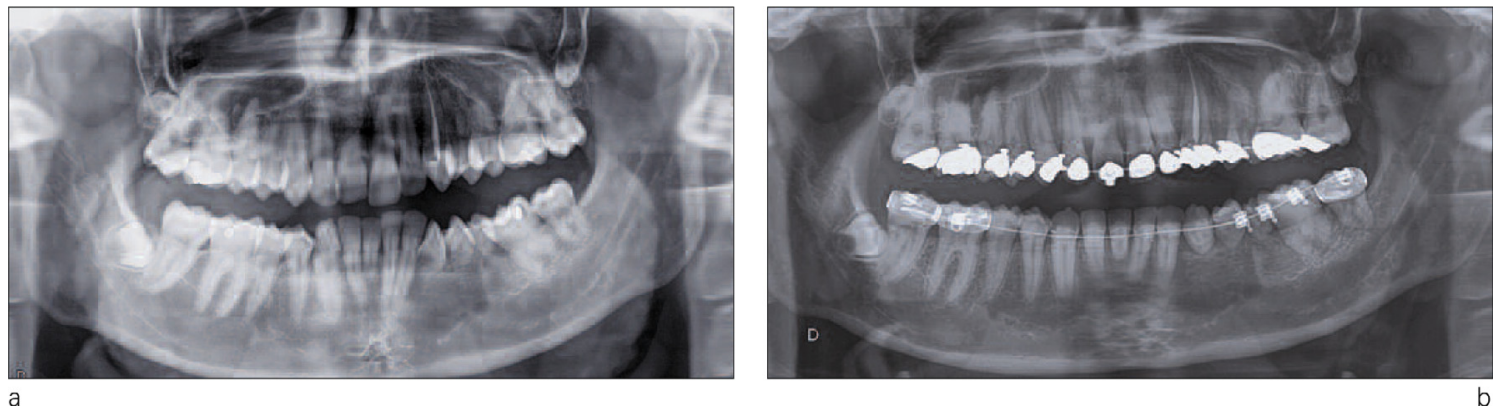

Figures 11a and 11b

Clinical case 3: Panoramic views.

a: Start of treatment. Note the "phantom" roots of the lower left cuspid and first and second bicuspids, and the markedly short roots of the upper right central incisor, the lower left central incisor, and the lower left first molar. b: After orthodontic treatment. Both arches have been leveled. Apical resorption of 11, 41, and 36 worsened, but the roots of 33, 34, and 35 appear stable. 


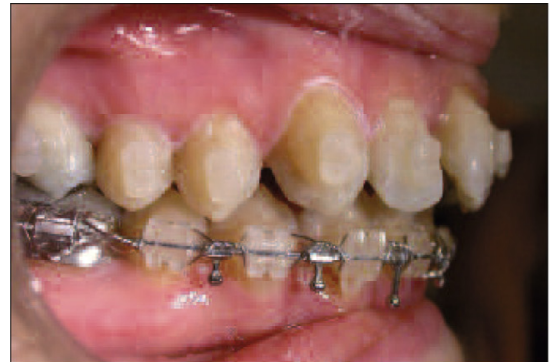

a

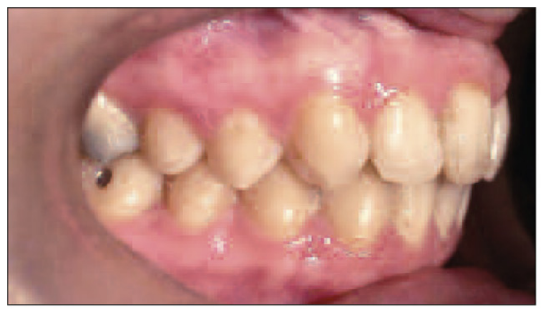

a

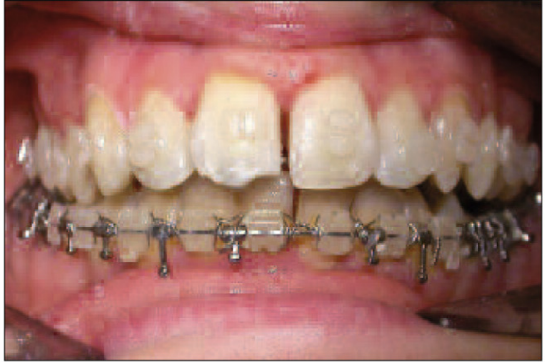

b

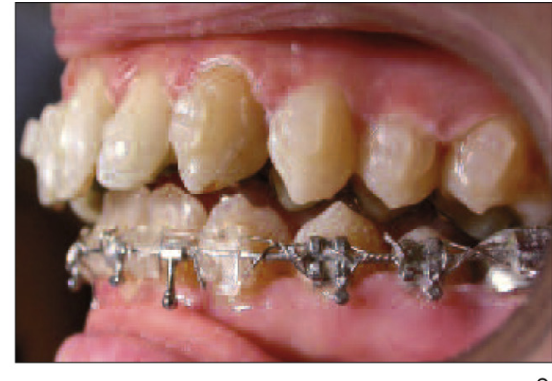

C

Figures $12 a$ to $12 c$

Clinical case 3: Intraoral views before surgery.

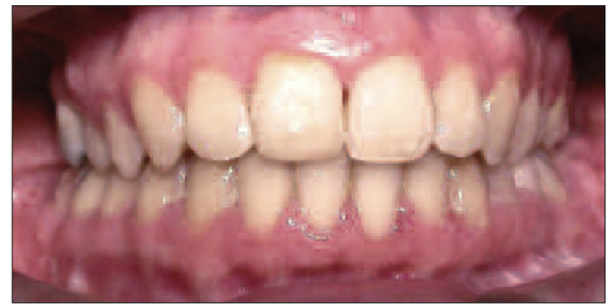

b

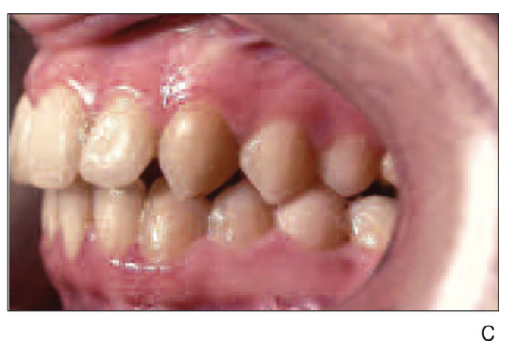

Figures 13a to $13 \mathrm{c}$

Clinical case 3: Intraoral views at the close of treatment.

more loss of buccal soft tissue attachment than healthy teeth. However, the correlation of occlusal interferences in centric relation to abfraction lesions or to a greater loss of attachment has not been demonstrated.

In conclusion, it is no longer deemed advisable to use selective grinding in an attempt to cure abfraction lesions ${ }^{30,36}$. Nevertheless, in the framework of orthodontic treatment, it may be worthwhile for orthodontists to discern specific areas of interference and to modify the values of lateral torque during finishing stages of treatment. Furthermore, to guard against bruxism, orthodontists may use thermoformed splints to afford mechanical protection to teeth that could be damaged by unhealthy constraints.

\section{- Occlusal trauma and periodontal damage}

Increased mobility of teeth associated with an enlargement of the periodontal ligament, a decrease in the visibility of the lamina dura, a loss of alveolar bone, or a change in the trabecular nature of maxillary or mandibular bone, as seen on radiographs, are all signs of occlusal trauma. The influence of occlusal factors in the development of periodontal disease is currently a controversial topic. Some authors still advocate occlusal 


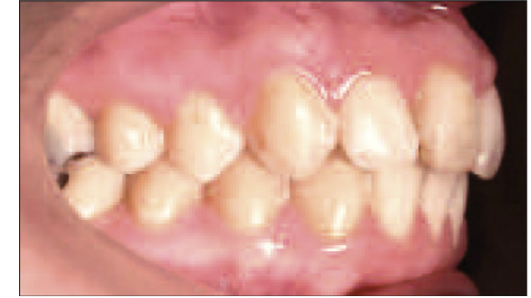

a

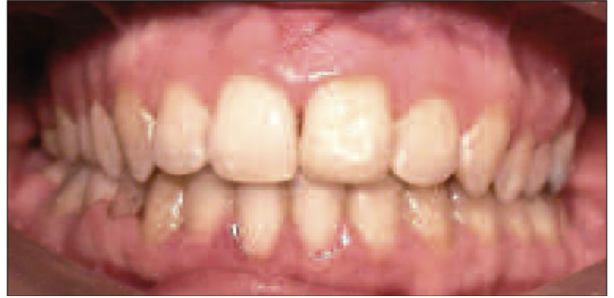

b

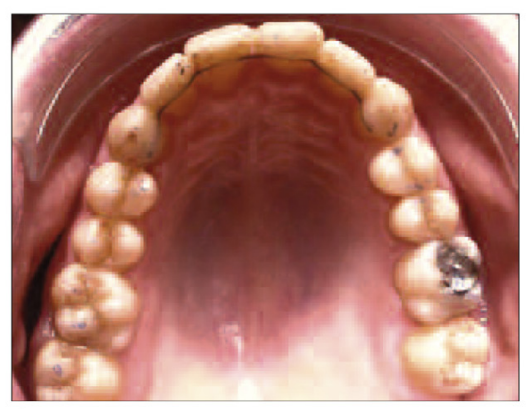

d

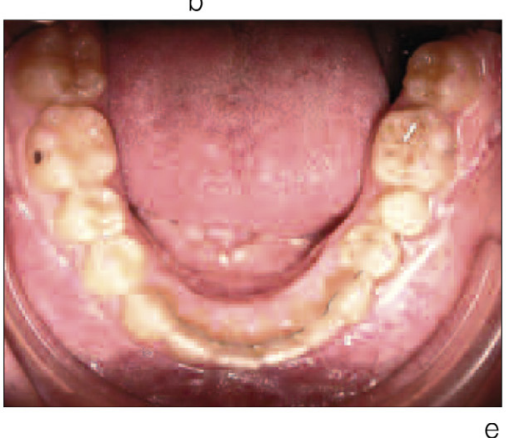

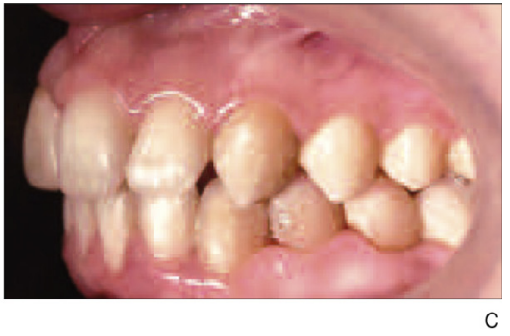

Figure 14

Clinical case 3: Intraoral views at the end of the retention period. We have added composite material to the hypoplastic teeth. equilibration as a component of a treatment plan aimed at regenerating periodontal tissue.

The influence of dynamic occlusal interferences on the depth of periodontal pockets was evaluated in a transverse epidemiological study of 2,980 subjects representative of a Caucasian population ${ }^{5}$. Their medical and dental histories and the different known periodontal risk factors were studied. Interferences on the nonworking side were shown to be significantly associated with pocket depth and loss of attachment $(P<0.0001)$, and there was an increase in pocket depth $(P=0.004)$ when a tooth had both working and non-working side contacts, with the amplitude of these forces having some influence on this outcome. These different relationships, even though clearly demonstrated, are not specific and are of little importance compared with other factors such as patient age, tobacco use, and plaque index.

Some older studies have shown that, despite occlusal trauma, periodontal disease can be successfully treated and stabilized ${ }^{15}$. However, occlusal trauma caused by high spots and interferences in lateral movements are found in cases of severe loss of alveolar bone and are positively correlated to the loss of periodontal attachment 6,10 .

\section{- Occlusal trauma and implants}

Dentists have not yet agreed on the general principles that should 
guide the management of implantsupported replacements for missing teeth. For example, different authorities have alternative opinions on whether occlusal interferences might be a causative factor in the loss of crestal bone around implants. Some clinicians fear that strong occlusal forces may have a deleterious effect on the long-term success of their implants by causing crown fracture or an osseointegration defect.

There is, however, a consensus that bacterial infection combined with immunosuppression are necessary to cause an implant failure and that, in certain cases, occlusal trauma could be an associated factor. Recent studies suggest that occlusal overload can lead to a loss of crestal bone in the absence of inflammation, but randomized prospective studies are needed to confirm this finding.
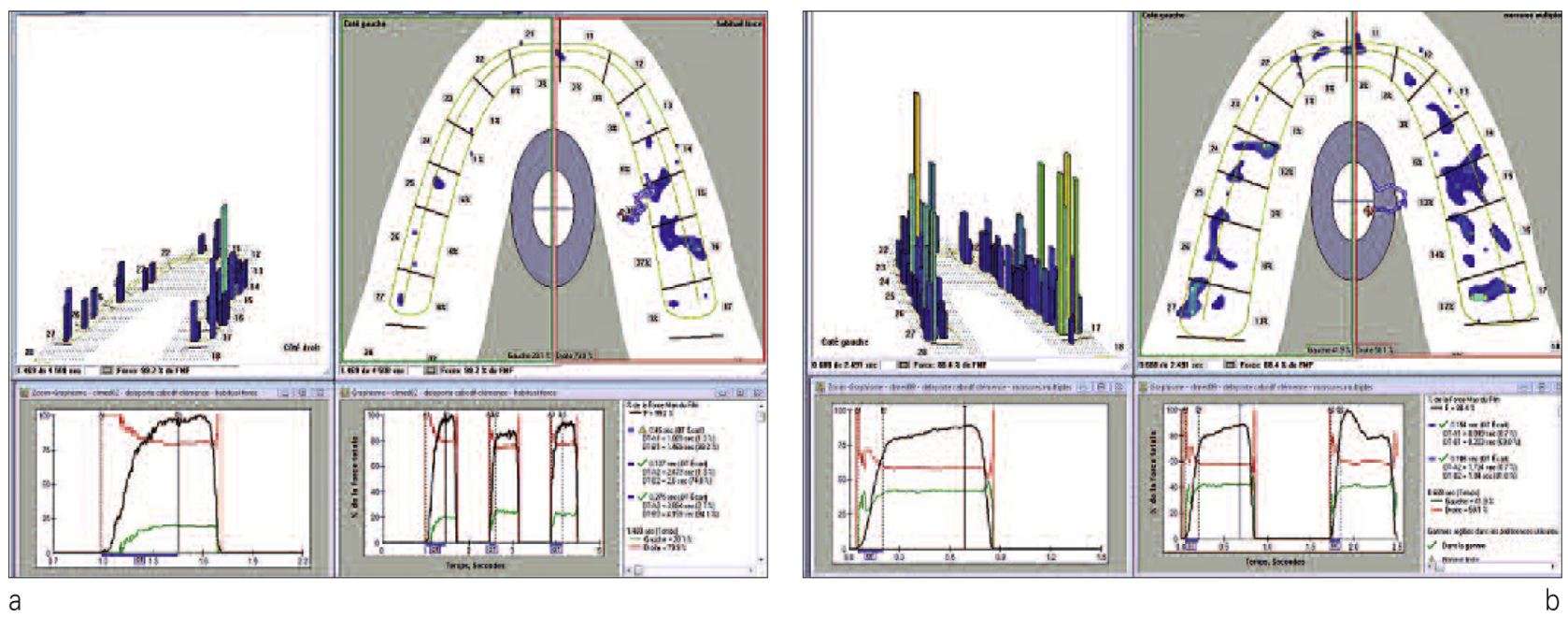

Figures $15 a$ and $15 b$

Clinical case3: T-scan III registration

$a$ and b: appliance removal appointment, showing the marked asymmetry of the inter-arch contacts, with $80 \%$ on the right side.

$c$ and $d$ : End of the 2-year retention period. The forces are almost centered, and are globally far more symmetric, with $60 \%$ on the right side and $40 \%$ on the left side. 


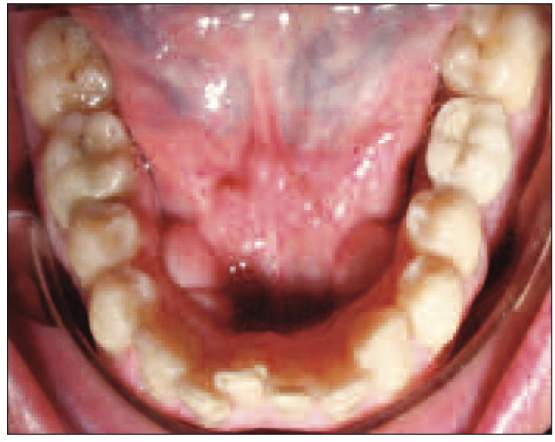

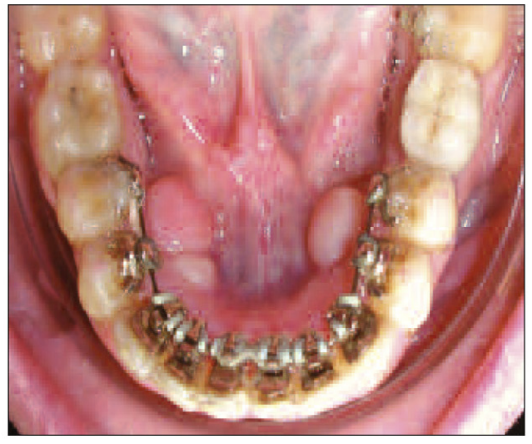

b

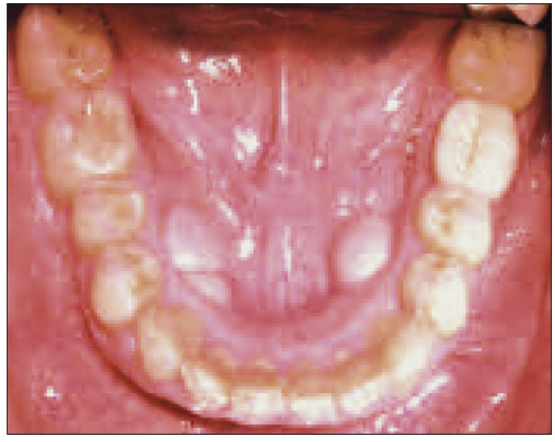

Figures 16a to $16 \mathrm{c}$

Clinical case 4: Treatment of a Class I malocclusion with an arch length discrepancy and anterior crowding associated with deep-bite. The lower left first prosthetic crown is supported by an implant (Dr. N. Cohen).

a: Lingual attachments were bonded from second bicuspid to second bicuspid

b: Lingual attachments were also placed on the entire upper arch.

c: Lower arch at the end of treatment. Note the mandibular tori.

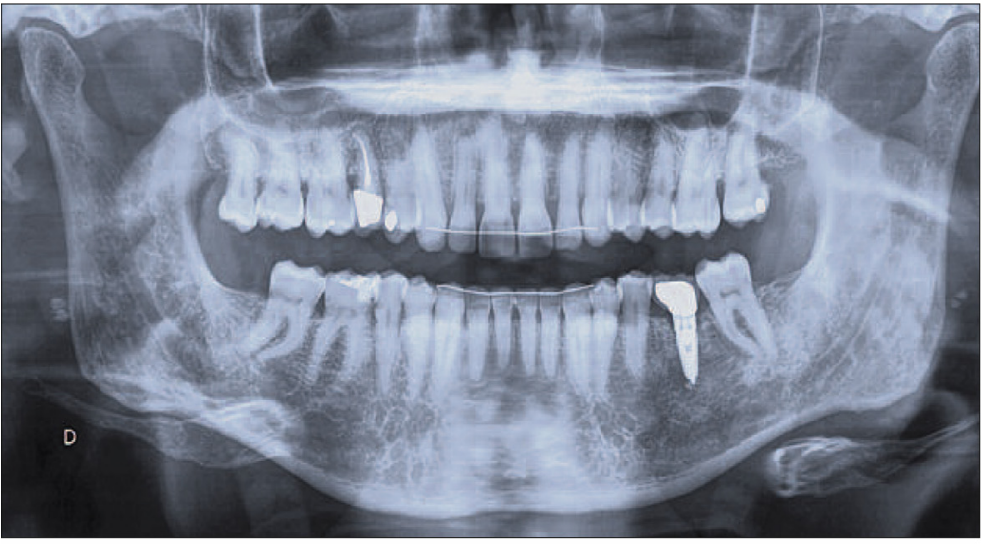

Figures $17 a$ and $17 b$ Clinical case 5 .

a

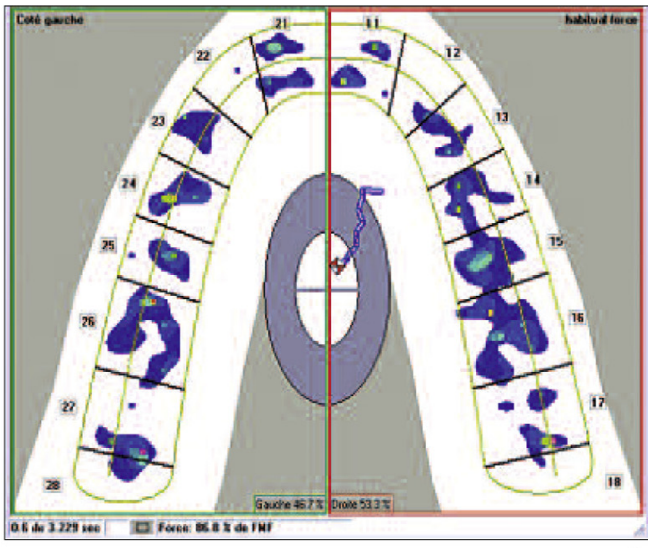

b

a: Panoramic radiograph at the end of treatment

b: T-scan III registration showing the distribution and excellent centering of forces.

occlusal loads. After removal of the stressed dental element, occlusal forces on the prosthesis were reduced and radiographic evidence showed partial repair of bone in the defect that affected several threads of the implant. Three years later bone levels remained stable. 


\section{4 - CONCLUSION}

The T-scan III system is a new computerized occlusal analysis tool that can provide an abundance of information, that might even exceed our present day clinical requirements.

Beyond the controversy over the effectiveness of occlusal equilibration as a treatment modality for abfraction lesions, periodontal defects, or bone loss around implants, the T-scan III system offers orthodontists immediate access to patient's functional oc- clusion. They can see the static and dynamic quality of inter-arch contacts in real time in a form that can be preserved in a record for comparison at any future date.

The T-scan III's precision, which can be quantified in milliseconds and square millimeters, has won recognition as a reliable and reproducible research tool.

\section{Conflict of interest}

The T-scan III sensor was graciously loaned to Dr. Cohen-Levy for clinical research, the results of which were published in 2011.

\section{REFERENCES}

1. American Association of Dental Research. Scientific information statement on temporomandibular disorders. AADR Reports 1996;18(4). AADR www.aadronline.org/i4a/ pages/index.cfm? pageid=3465.

2. Amat $P$. Prise en charge thérapeutique des DAM par rééducation maxillo-faciale, intégrée à une éducation thérapeutique du patient : pourquoi, quand, comment ? Rev Orthop Dento Faciale 2011:45:175-185.

3. An WW, Wang BK, Bai YX. [Occlusal contacts in intercuspal position after orthodontic treatment]. Zhonghua Kou Qiang Yi Xue Za Zhi 2009;44(12):735-8.

4. Baba K, Tsukiyama Y, Clark GT. Reliability, validity, and utility of various occlusal measurement methods and techniques. J Prosthet Dent 2000;83(1):83-9.

5. Bernhardt O, Gesch D, Look JO, Hodges JS, Schwahn C, Mack F, Kocher TJ. The influence of dynamic occlusal interferences on probing depth and attachment level: results of the Study of Health in Pomerania (SHIP). J Periodontol 2006;77(3):506-16.

6. Branschofsky M, Beikler T, Schäfer R, Flemming TF, Lang H. Secondary trauma from occlusion and periodontitis. Quintessence Int 2011;42(6):515-22.

7. Cohen-Levy J, Cohen N. Occlusal contacts analysis after lingual orthodontic treatment in the adult patient with a computerized system. Int Orthod 2011 Dec; (in press).

8. Cohen-Levy J, Pasquet G, Cavézian R. Réflexion radio «logique»: à propos de résorptions radiculaires... Rev Orthop Dento Faciale 2007;41:483-6.

9. Carey JP, Craig M, Kerstein RB, Radke J. Determining a relationship between applied occlusal load and articulating paper mark area. Open Dent J 2007;1:1-7.

10. Chambrone L, Chambrone LA, Lima LA. Effects of occlusal overload on peri-implant tissue health: a systematic review of animal-model studies. J Periodontol 2010;81(10):1367-78. 
11. Ciavarella D, Parziale V, Mastrovincenzo $M$, Palazzo A, Sabatucci A, Suriano MM, Bossù M, Cazzolla AP, Lo Muzio L, Chimenti C. Condylar Position Indicator and TScan system II in clinical evaluation of temporomandibular intracapsular disease. J Craniomaxillofac Surg 2011;29.

12. Clark GT, Tsukiyama Y, Baba K, Simmons M. The validity and utility of disease detection methods and of occlusal therapy for temporomandibular disorders. Oral Surg Oral Med Oral Pathol Oral Radiol Endod 1997;83(1):101-6.

13. Deroze D, Lacout J. Finitions occlusales, occlusion fonctionnelle, élastopositionnement. Pourquoi, comment ? Àpropos d'un cas. Rev Orthop Dento Faciale 2011; 45:207-20.

14. Fricton J, Look JO, Wright E, Alencar FG Jr, Chen H, Lang M, Ouyang W, Velly AM. Systematic review and meta-analysis of randomized controlled trials evaluating intraoral orthopedic appliances for temporomandibular disorders. J Orofac Pain 2010;24(3):237-54.

15. Gher ME. Changing concepts. The effects of occlusion on periodontitis. Dent Clin North Am 1998; 42(2):285-99.

16. Hämmerle $\mathrm{CH}$, Wagner $D$, Brägger $U$, Lussi $A$, Karayiannis $A$, Joss $A$, Lang NP. Threshold of tactile sensitivity perceived with dental endosseous implants and natural teeth. Clin Oral Implants Res 1995; 6(2):83-90.

17. Harvey WL, Osborne JW, Hatch RA. A preliminary test of the replicability of a computerized occlusal analysis system. J Prosthet Dent 1992;67(5):697-700.

18. Hsu M, Palla S, Gallo LM. Sensitivity and reliability of the T-scan system for occlusal analysis. J Craniomandib Disord 1992;6:17-23.

19. Iwase M, Sugimori M, Kurachi Y, Nagumo M. Changes in bite force and occlusal contacts in patients treated for mandibular prognathism by orthognathic surgery. J Oral Maxillofac Surg 1998;56(7):850-5; discussion 855-6.

20. Kerstein RB. Articulating paper mark misconceptions and computerized occlusal analysis technology. Dent Implantol Update 2008;19(6):41-6.

21. Kerstein RB. Combining technologies: a computerized occlusal analysis system synchronized with a computerized electromyography system. Cranio 2004;22(2):96-109.

22. Kerstein RB, Lowe M, Harty M, Radke J. A force reproduction analysis of two recording sensors of a computerized occlusal analysis system. Cranio 2006;24(1):15-24.

23. Kerstein RB. T-scan III applications in mixed arch and complete arch, implant -supported prosthodontics. Dent Implantol Update 2008;19(7):49-53.

24. Koos B, Godt A, Schille C, Göz G. Precision of an instrumentation-based method of analyzing occlusion and its resulting distribution of forces in the dental arch. J Orofac Orthop 2010;71(6):403-10.

25. Leung KC, Chow TW, Wat PY, Comfort MB. Peri-implant bone loss: management of a patient. Int J Oral Maxillofac Implants 2001;16(2):273-7.

26. Lindenmeyer A, Sutcliffe P, Eghtessad M, Goulden R, Speculand B, Harris M. Oral and maxillofacial surgery and chronic painful temporomandibular disorders - a systematic review. J Oral Maxillofac Surg 2010;68(11):2755-64.

27. Luther F, Layton S, McDonald F. Orthodontics for treating temporomandibular joint (TMJ) disorders. Cochrane Database Syst Rev 2010;(7):CD006541.

28. Lyotard N, Hans M, Nelson S, Valiathan M. Short-term postorthodontic changes in the absence of retention. Angle Orthod 2010;80(6):1045-50.

29. Maness WL, Benjamin M, Podoloff R, Bobick A, Golden RF. Computerized occlusal analysis: a new technology. Quintessence Int 1987;18(4):287-92.

30. Michael JA, Townsend GC, Greenwood LF, Kaidonis JA. Abfraction: separating fact from fiction. Aust Dent J 2009;54(1):2-8.

31. Millstein $P$, Maya A. An evaluation of occlusal contact marking indicators. A descriptive quantitative method. J Am Dent Assoc 2001;132(9):1280-6; quiz 1319. 
32. Mizui M, Nabeshima F, Tosa J, Tanaka M, Kawazoe T. Quantitative analysis of occlusal balance in intercuspal position using the T-Scan system. Int $\mathrm{J}$ Prosthodont 1994;7(1):62-71.

33. Montgomery MW, Shuman L, Morgan A. T-scan dental force analysis for routine dental examination. Dent Today 2011;30(7):112-4,116.

34. Misch CE, Suzuki JB, Misch-Dietsh FM, Bidez MW. A positive correlation between occlusal trauma and peri-implant bone loss: literature support. Implant Dent 2005;14(2):108-16.

35. Orthlieb J.-D. Éditorial. Le bon, la brute et I'A.T.M. Rev Orthop Dento Faciale 2011;45:119-120.

36. Reyes E, Hildebolt C, Langenwalter E, Miley D. Abfractions and attachment loss in teeth with premature contacts in centric relation: clinical observations. J Periodontol 2009;80(12):1955-62.

37. Rozencweig D., Rozencweig G., Rozencweig S. Occlusodontie. Comment trouver plus aisément les points de contact. Rev Orthop Dento Faciale 2011;45:221-2.

38. Saad MN, Weiner G, Ehrenberg D, Weiner S. Effects of load and indicator type upon occlusal contact markings. J Biomed Mater Res B Appl Biomater 2008;85(1):18-22.

39. Saraçoglu A, Ozpinar B. In vivo and in vitro evaluation of occlusal indicator sensitivity. J Prosthet Dent 2002;88(5):522-6.

40. Wang YL, Cheng J, Chen YM, Yip KH, Smales RJ, Yin XM. Patterns and forces of occlusal contacts during lateral excursions recorded by the T-Scan II system in young Chinese adults with normal occlusions. J Oral Rehabil 2011;38(8):571-8. doi:10.1111/ j.1365-2842.2010.02194.x. 